\section{PRE-CAMBRIAN ROCK}

\section{Origin of Anorthosite and Related Rocks}

Edited by Y. W. Isachsen. (Papers presented at the Second Annual George H. Hudson Symposium at Plattsburgh, New York, 1966.) (Memoir 18, New York State Museum and Science Service.) Pp. ix +466 . (University of New York State Education Department: Albany, New York, 1969.) $\$ 20$.

Massive bodies of anorthosite, a rock consisting of plagioclase feldspar together with minor amounts of iron-, magnesium- and titanium-bearing minerals occur in Pre-Cambrian Shield areas affected by orogenesis in the period 1,000-2,000 m.y. ago. Single bodies may exceed $20,000 \mathrm{sq} \mathrm{km}$ in area and are thus the largest masses of monomineralic igneous rock exposed at the Earth's surface. This volume of symposium papers records the divergence of opinions in 1966 on the origin of massive anorthosite among the majority of the geologists then working on the subject. Y. W. Isachsen, who had the unenviable task of summarizing the contrasting viewpoints expressed, has ably edited the volume.

The papers form an essential reference book for geologists working on anorthosites and their spatially associated rocks such as mangerites and rapakivi granites. They provide considerable information for those working in high grade metamorphic terrains and, because massive anorthosites seem to have formed particularly abundantly during one period in Earth history, the volume should be required reading for all those who wish to discuss possible evolutionary changes in the crust of our planet. The general standard of individual papers is high and the summaries and review articles are invaluable reference sources. There is, however, an unfortunate tendency to use chemical, statistical and isotopic data to "prove" a particular hypothesis about the genesis of these rocks without sufficient consideration of the relevance of the investigation to the problem studied.

The fundamental paradox of massive anorthosites is that they have textures, structures and minerals which appear identical with those found in rocks known to have crystallized from a normal rock melt; at the same time having a bulk chemical composition which is unlikely ever to have oceurred as a major rock melt under normal terrestrial processes. Accepting an igneous origin for these rocks, there are four important questions which have to be answered before the formation and significance of anorthosites can be understood: (1) the geological environment under which the anorthosites were emplaced; (2) the relationship between the anorthosites and the spatially associated monzonites, mangerites and granitic rocks; (3) the derivation and composition of the parent magmas; (4) assuming a normal parent magma, the mechanism by which feldspar was accumulated or segregated to form a massive monomineralic rock.

Two major groups of massive anorthosite were recog. nized at the symposium: (i) a group of post orogenic intrusions emplaced in areas affected by earlier meta. morphism between 1,600-2,000 m.y. ago-these are particularly well developed in Labrador and are generally thought to have crystallized from a basaltic parent magma; (ii) a group of anorthosites involved in orogenesis around 1,000-1,200 m.y. ago. Many contributors regarded the second group as meta-anorthosites intruded under similar conditions to the first group, but affected by later meta. morphism and tectonism. Other contributors regarded this second type as syn-orogenic and ascribe their characters to original features formed under regional high grade metamorphic conditions. Those subscribing to this view suggested a variety of parent magmas, the most common of which was a dioritic or quartz dioritic melt produced at depth in orogenic zones.

Most of those who have worked on anorthosites in both environments have been impressed by their essential similarity. While there certainly are local variations, there seems a good case for regarding the formation of these rocks as a single problem. The different hypotheses put forward in this book probably diverge from each other more than the rocks themselves do. It is to be hoped that the publication of these views in a single volume will stimulate further work on the rocks.

The abundance of these bodies at one particular time in Earth history suggests that massive anorthosites were formed under particular combinations of temperature and pressure which were unique to the mid-Pre-Cambrian. One suggestion could be that their genesis requires the presence of a thick crust combined with high heat flow. When the problems of the formation of massive anorthosites are solved we will know much more not only about these intriguing rocks but also about the nature of the Earth's crust at one stage in its development.

\section{DAVID BRIDGWATER}

\section{FIGURING THE EARTH}

\section{Introduction to Geodesy}

By Clair E. Ewing and Michael M. Mitchell. Pp. x+304. (Elsevier: New York and Barking, Essex, 1970.) $155 \mathrm{~s}$.

Althougr geodesy developed rapidly during the late eighteenth and early nineteenth centuries, developments since then have, until recently, been slow. This is mirrored in the literature of the subject in English, as, after A. R. Clarke published his famous Geodesy in 1880, it was not until 1952 that a new comprehensive treatise was published by Bomford. Both these books are directed primarily at the surveyor/geodesist and are not suitable for students or for those working in related fields who require only a general knowledge of the subject. Recent fundamental advances in geodesy and great increases in the numbers working in related fields have created a demand for an introductory book and Ewing and Mitchell have attempted to meet this demand.

Their book deals briefly with the more traditional aspects of the subject-figures of the Earth, astronomical determinations, gravity measurements and geodetic triangulation and levelling - and more fully with the new topics of electronic surveying and the geodetic uses of satellite observations; there are also chapters on coordinate systems and on the adjustment of observations.

By electronic surveying, the authors mean the use of electromagnetic waves to determine distances and the geodetic use of these distances. This is an important topic and it is unfortunate that the authors have trivialized it by concentrating on a general account of the various equipments and techniques, many of them now obsolete, used during the past twenty years and devoting comparatively little space to fundamental theory.

The chapter on satellites is the best part of the book and in view of the American predominance in this field this is not surprising. The basic theory is outlined without too much emphasis on the hardware. The chapter on adjustments is satisfactory and that on coordinate systems is good because it introduces non-classical geodesy which is a topic of growing importance.

On the debit side the authors deal far too superficially with the classical aspects of the subject, particularly astronomical observations, and the writing is slipshod with many inaccurate and misleading statements. This last fault is really unforgivable in any textbook and detracts seriously from the value of this one.

\section{P. J. CARMODY}

\section{SPACE PHYSICS}

\section{Space Physics}

By R. Stephen White. Pp. xi + 318. (Gordon and Breach: London and New York, April 1970.) 105s; $\$ 12.60$.

For a long time university lecturers have been waiting for a good textbook on space physics to help them teach 